\title{
Sensitivity analysis for joint inversion of ground-penetrating radar and thermal-hydrological data from a large-scale underground heater test
}

\author{
M. B. Kowalsky, J. Birkholzer, J. Peterson, S. Finsterle, S. Mukhopadhyay, and Y. Tsang \\ Earth Sciences Division, Lawrence Berkeley National Laboratory, 1 Cyclotron Road, MS 90- \\ 1116, Berkeley, CA 94720
}

\begin{abstract}
We describe a joint inversion approach that combines geophysical and thermal-hydrological data for the estimation of (1) thermal-hydrological parameters (such as permeability, porosity, thermal conductivity, and parameters of the capillary pressure and relative permeability functions) that are necessary for predicting the flow of fluids and heat in fractured porous media, and (2) parameters of the petrophysical function that relates water saturation, porosity and temperature to the dielectric constant. The approach incorporates the coupled simulation of nonisothermal multiphase fluid flow and ground-penetrating radar (GPR) travel times within an optimization framework. We discuss application of the approach to a large-scale in situ heater test which was conducted at Yucca Mountain, Nevada, to better understand the coupled thermal, hydrological, mechanical, and chemical processes that may occur in the fractured rock mass around a geologic repository for high-level radioactive waste. We provide a description of the time-lapse geophysical data (i.e., cross-borehole ground-penetrating radar) and thermalhydrological data (i.e., temperature and water content data) collected before and during the fouryear heating phase of the test, and analyze the sensitivity of the most relevant thermalhydrological and petrophysical parameters to the available data. To demonstrate feasibility of the approach, and as a first step toward comprehensive inversion of the heater test data, we apply the approach to estimate one parameter, the permeability of the rock matrix.
\end{abstract}




\section{INTRODUCTION}

Understanding and predicting the movement of fluids in the subsurface is critical for a variety of applications such as environmental remediation; $\mathrm{CO}_{2}$ sequestration; salt water intrusion into fresh water aquifers; production from oil, gas, and geothermal reservoirs; and nuclear waste disposal. In order to develop site-specific hydrological models, characterization efforts increasingly involve analysis of hydrological and geophysical data. However, the merit of any given data type depends on its usefulness in providing quantitative information about flow and transport properties (at a reasonable resolution). While geophysical data potentially offer valuable information about flow and transport processes, methods for integrating such data sets with hydrological data sets are still at early stages of development.

Conventional interpretation of cross-borehole seismic or ground-penetrating radar (GPR) data involves tomographic imaging, ${ }^{\mathrm{i}}$ in which the distributions of geophysical attributes like velocity and attenuation are obtained. In some cases hydrological data can be mapped to the tomographic imaging plane, for example, when a good correlation exists between the geophysical attributes and co-located hydrological data. ${ }^{\text {ii-iii }}$ However, integrating tomographic data into a hydrological modeling framework can be problematic due to difficulties inherent to the tomography procedure, ${ }^{\mathrm{iv}-\mathrm{v}}$ and due to uncertainty in the relationship between the geophysical attributes and the hydrological parameters of interest. ${ }^{\text {vivvii }}$

A more fundamental limitation to such an approach is that geophysical attributes can in general not be directly related to the parameters needed for hydrological modeling. This is especially true in the vadose zone, where variations in water saturation dramatically affect the signal and potentially cause non-uniqueness in the relationship between geophysical attributes and hydrological properties. For example, it is well known that GPR data are sensitive to spatial and temporal variations in water saturation, ${ }^{\text {vii-ix }}$ because of good correlation between the soil 
water content and the dielectric constant (see review by Huisman et al. ${ }^{x}$ ). However, these geophysical data cannot be directly related to the hydraulic properties, such as the absolute permeability and the parameters describing the relative permeability and capillary pressure functions, which are needed to make hydrological modeling predictions. On the other hand, it has been recognized that time-lapse GPR data contain information that can be indirectly related to the soil hydraulic properties, since these hydraulic properties influence the time- and spacevarying changes in water distribution, which in turn affect GPR data. ${ }^{\text {xixii }}$

Recently we developed an approach for estimating soil hydraulic parameter distributions by incorporating time-lapse GPR measurements and measurements of hydrological properties

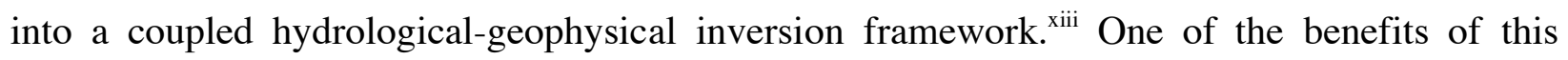
approach is that it directly uses GPR travel times without requiring creation of velocity tomograms, thus alleviating difficulties inherent to tomographic inversion and also allowing for collection of sparser GPR data sets relative to those required for conventional tomography. We further extended the approach to account for uncertainty in the petrophysical function (the relationship between water content and the dielectric properties) and to increase the flexibility of GPR data that can be considered (to include multiple offset data acquisition in three dimensions), allowing increased resolution and accuracy of soil hydraulic parameter estimates, ${ }^{\text {xiv }}$ and to account for uncertainty in the spatial correlation patterns of subsurface parameters. ${ }^{\mathrm{xv}}$

Until now, application of our approach was limited to experiments involving water injection in porous media. Here we extend the approach to consider applications involving more complex hydrological processes, including the transport of water, water vapor, air and heat in fractured porous media, as well as transitions between the liquid and gaseous phases, and vapor pressure lowering effects as a result of capillary pressure increases. In addition to incorporating geophysical (GPR travel time data) and hydrological data (water content data derived from 
neutron logging), we also consider temperature measurements and thus the possibility of estimating thermal parameters of the hydrological and geophysical models. We discuss application of the approach to a large-scale heater test performed at Yucca Mountain, Nevada.

\section{BACKGROUND}

A large-scale in situ heater test, the Drift Scale Test (DST), was conducted by the United States Department of Energy (DOE) at Yucca Mountain, Nevada, in order to better understand the coupled thermal, hydrological, mechanical, and chemical processes that may occur in the fractured rock mass around a geologic repository for high-level radioactive waste. ${ }^{\text {xi }}$ (An overview of additional field work performed at Yucca Mountain is given by Bodvarsson et al. ${ }^{\text {xii }}$ ) The DST is located in the unsaturated zone of the nonlithophysal unit of the Topopah Spring welded tuff, ${ }^{\text {xviii }}$ which contains a rock matrix of very low permeability, and which is heavily fractured with highly permeable, well connected fractures. Tsang et al. ${ }^{\text {xix }}$ discuss the extensive characterization and modeling that preceded the DST.

The intent of the DST was to create, within the time-frame of the experiment, conditions similar to those expected in a potential nuclear waste repository after 50 to 100 years. To mimic the expected release of heat from radioactive decay, nine heater canisters were placed along a tunnel (heated drift) approximately 50 meters in length and 5 meters in diameter, and 50 additional heaters (wing heaters) were positioned in regularly spaced boreholes that extend perpendicularly from the heated drift in both horizontal directions (Fig. 1). Temperature sensors were installed in radial arrays (in increments of 45 degrees) of 20-meter-long boreholes that were perpendicular to the heated drift. In addition, a second tunnel (observation drift) was constructed parallel to the heated drift, at a distance of approximately 30 meters, to allow for installation of and access to a large number of boreholes spanning the area above and below the heated drift, 
and in between the heated drift and the observation drift. Boreholes originating from the observation drift, 40 meters in length, were instrumented to measure thermal, hydrological, chemical and mechanical properties of the fractured rock mass surrounding the heated drift during the test; some of these boreholes were also used for collecting geophysical data.

Of interest in the current study are time-lapse data collected before and during the 4 year heating phase of the DST including geophysical (GPR), hydrological (water content data derived from neutron logging), and thermal data. In addition to allowing for the accuracy of predictive hydrogeological models to be evaluated, ${ }^{x i}$ these data sets provide a unique opportunity to evaluate methods for estimating thermal-hydrological and geophysical parameters.

\section{THERMAL-HYDOLOGICAL MODEL}

The non-isothermal multiphase flow simulator TOUGH2 (with equation-of-state module EOS4) is used here to model the complex thermal-hydrological phenomena of interest including the transport of water, water vapor, air and heat in fractured porous media, as well as transitions between the liquid and gaseous phases, and vapor pressure lowering effects. ${ }^{\mathrm{xx}}$ To account for the presence of high-permeability fractures embedded in a low-permeability matrix, a dualpermeability model is used, casting the matrix and fractures as two separate but interacting continua. $^{\text {xxi }}$

As described in detail by Birkholzer and Tsang, ${ }^{\text {xi }}$ the following complex thermalhydrological processes are expected to occur as a result of the increased heat due to the decay of high-level radioactive waste (with formation temperatures exceeding $100^{\circ} \mathrm{C}$ ). As matrix pore water in the vicinity of a heat source is heated to its boiling point, it vaporizes, enters the highly permeable fractures, and migrates either away from the heat source or into the heated drift. When the vapor in the fractured rock travels some distance from the heated regions, it comes into 
contact with cooler rock, at which point it condenses, increasing the liquid saturation in the fractures. The condensate may then imbibe into the matrix and be drawn back to the heat source due to capillary suction or it may drain elsewhere under the force of gravity. With time a dry-out zone in the vicinity of the heat source develops. The parameters that are most important for characterizing such a system include permeability, porosity, and parameters of the capillary pressure function for both the matrix and fracture continua. In addition, it is believed that at Yucca Mountain not all connected fractures conduct water, and consequent reduction in the flux between the matrix and fractures must be accounted for to accurately model unsaturated flow and transport. $^{\text {xxii }}$ Therefore, we also consider the parameter $\gamma$ of the active fracture model ${ }^{\text {xii }}$ as a parameter of potential importance for characterization. The fraction of active fractures (i.e., the fractures through which unsaturated flow occurs) is assumed equal to the effective water saturation raised to the power of the parameter $\gamma$.

The model used in this study is similar to the model that was initially developed, ${ }^{\mathrm{xxiii}}$ and further refined, ${ }^{\text {xi,xxiv }}$ to accurately represent the test geometry and conditions at the site. Rather than subdivide the Topopah Spring welded tuff system into three stratigraphic subunits, we use a simplified version of the model in which the material properties of the middle nonlithophysal unit (tptpmn) are used throughout the entire model domain. The capillary suction and relative permeability functions used for the liquid phase are based on the van Genuchten functions, ${ }^{\mathrm{xxv}}$ while those for the gas phase are based on those by Brooks and Corey. ${ }^{\text {xxi }}$ Additional details of the thermal-hydrological model are described by Birkholzer and Tsang. ${ }^{\text {xvi }}$

At present we focus our modeling efforts on a two-dimensional cross section (Fig. 2a) perpendicular to and approximately $12 \mathrm{~m}$ from the start of the heated drift. A two-dimensional representation is reasonable over most of the 50-meter-long drift, except near the ends. The temperature, water content, and GPR data we consider were collected in boreholes perpendicular 
to the heated drift (Figs. 2b and 2c) at nearby locations (approximately 12 and $6 \mathrm{~m}$, respectively, from the start of the heated drift). Temperature and water content measurements (along with GPR measurements, as described below) are simulated within the framework of iTOUGH2, ${ }^{\text {xvii- }}$ xxviii a code that provides inverse modeling capabilities for TOUGH2.

\section{GEOPHYSICAL MODEL}

GPR measurements can be simulated with varying degrees of accuracy and computational efficiency depending on the forward model. The most accurate (and computationally intensive) methods are full waveform methods, which require solution of the Maxwell equations either in the frequency or time domain. ${ }^{x i x}$ Ray-based methods are more computationally efficient (though potentially less accurate), mainly aiming to model the first arrival of energy traveling between transmitting and receiving antennas. Of the ray-based methods, the straight-ray method is the most efficient, especially for implementation in threedimensional models and in inversion algorithms - such as the one being developed here - that require iterative solution of the forward model.

Here we use the straight-ray method for which a GPR travel time $T$ is calculated by defining a straight ray between the antennas and summing the travel times in each grid block through which the ray passes:

$$
T=\sum_{i=1}^{N} \frac{L_{i}}{V_{i}}=\sum_{i=1}^{N} L_{i} \frac{\sqrt{\kappa}_{i}}{c}
$$

Here $L_{i}$ is the length of the travel path (linear line segment) in block $i, N$ is the number of blocks through which the ray passes, and $V_{i}$ is the electromagnetic velocity in block $i$, related to the dielectric constant of the soil/water/gas mixture $\kappa_{i}$. Kowalsky et al. ${ }^{\text {xiv }}$ provide a discussion on the applicability of the straight-ray approach. 
The relationship between the dielectric constant and the soil properties is commonly modeled with a volumetric mixing model:

$$
\kappa=\left[(1-\phi) \kappa_{s}^{n}+S \phi \kappa_{w}^{n}+(1-S) \phi \kappa_{a}^{n}\right]
$$

where $\phi$ is the porosity of the rock matrix, $n$ is a parameter related to the geometric arrangement of materials, ${ }^{\mathrm{xxxi}}$ commonly assumed to be 0.5 , as is expected in isotropic media, ${ }^{\text {xxiii }}$ but observed to vary between 0.4 and $0.65 .{ }^{\text {xxiv }}$ The dielectric constants for the solid grain, water and air components are given, respectively, by $\kappa_{s}, \kappa_{w}$ and $\kappa_{a}$.

Temperature dependence of the dielectric properties at the site considered in this study must be accounted for given the extreme changes in temperature occurring during the heater test (ranging from the ambient temperature to values exceeding $200^{\circ} \mathrm{C}$ ). While the dielectric constants of air and solid grains are expected to be unaffected by temperature, that of water is known to be temperature dependent. ${ }^{\mathrm{xxx}}$ At present we assume that for temperatures less than the boiling point of water the dielectric constant can be accurately described with the expression given by Weast: ${ }^{\mathrm{xxxv}}$

$$
\kappa_{w}=78.54\left(1-4.579 \times 10^{-3}(T-25)+1.19 \times 10^{-5}(T-25)^{2}-2.8 \times 10^{-8}(T-25)^{3}\right),
$$

where $T$ is the temperature $\left[{ }^{\circ} \mathrm{C}\right]$. The dielectric constant of water vapor is assumed to be that of air. In-depth discussions on temperature dependence of the dielectric constant are given by Wraith and $\mathrm{Or}^{\mathrm{xxxvi}}$ and Roberts and Lin. ${ }^{\mathrm{xxxvii}}$

The combination of Eqs. (1) - (3) comprises the forward model for calculating the GPR travel times within iTOUGH2. Coupling between the thermal-hydrological model and the geophysical model is uni-directional, with distributions of saturation and temperature simulated by the thermal-hydrological model at given times, along with the porosity distribution (which in 
the current work is assumed homogeneous), being transferred to the GPR forward model for calculation of the travel times.

\section{DESCRIPTION OF MEASUREMENTS}

Cross-borehole GPR measurements were collected between several boreholes before and during the heater test. Here we consider only the data collected between Boreholes 3 and 4 (see Fig. 2c) before the heating had begun (P0) and at four additional times: 74 days (P1); 426 days (P2); 533 days (P3); and 694 days (P4) after the onset of heating. Note that while data were collected for the duration of heating and beyond, we focus on the early phase of heating at present. Fig. 3 shows the complete data sets collected at three times $(a-c)$ and the subsets of these data sets, with ray density increasing toward the region of interest in the test, actually used for the inversion (d-f). The horizontal axes in the figure give the horizontal antenna position ( $\mathrm{x}$ axis) in Borehole 4, while the vertical axes in the figure give the horizontal antenna position ( $\mathrm{x}$ axis) in Borehole 3. The GPR travel times between positions in Boreholes 3 and 4 are also shown in Fig. 3a-c. In general, larger travel times correspond to longer travel paths between the transmitting and receiving antennas. As the heater test progresses (with increasing survey time), the rock begins to dry near the drift wall $($ at $x=-2.5 \mathrm{~m})$, and the travel times near this region $(\mathrm{x}=$ -15 to $-5 \mathrm{~m}$ ) decrease, since the dielectric constant decreases with decreasing water saturation (corresponding to an increased electromagnetic velocity). Note that the combinations of transmitting and receiving antenna positions were slightly different for each survey.

Water content data (derived from neutron-probe measurements) were collected in $10 \mathrm{~cm}$ increments at time intervals of approximately 30 days in Boreholes 3-5 (see Fig. 2b and Fig. 4). From the dense data collected for each borehole (left column in Fig. 4), data at only 5 survey times ( $\mathrm{P} 0$ - P4, as defined above and as shown in the right column in Fig. 4) are used at present 
for inversion. Note that the drying front has reached Borehole 4 by time P2. By survey time P4, the region between $x=-15$ and $x=-5 \mathrm{~m}$ appears to have dried out. The drying front does not reach Boreholes 3 or 5 by the final survey time we consider (P4). Data points collected in the space of an individual grid block of the thermal-hydrological model (shaded blue in Fig. 2) were averaged in order to be compared with simulated values during the inversion, giving a total of 475 water content data points $(25,39$, and 31 points in Boreholes 3,4 and 5, respectively, collected at 5 survey times).

Temperature data were collected in 8 boreholes (Boreholes 137-144; see Fig. 2b) at 6 hour intervals using approximately 535 sensors nominally spaced in $30 \mathrm{~cm}$ intervals. Similar to the water content data, we consider a small subset of the available data, that is, only the data collected at the same 5 survey times (P0 - P4). Data points collected in the space of an individual grid block of the thermal-hydrological model (shaded red in Fig. 2) were averaged in order to be compared with the simulated values during the inversion, giving a total of 780 temperature data points (corresponding to between 15 and 24 data points at 5 times in each borehole).

\section{RESULTS}

Before conducting time-consuming inversions, it is useful to perform sensitivity analyses to help determine which parameters can be accurately estimated. ${ }^{\text {xxviii }}$ In general, the higher the sensitivity of the data to the parameters of interest, the better the chances of being able to estimate the parameters through joint inversion. Such studies allow for the contribution of individual data sets (e.g., GPR travel times, temperature, water content) in the estimation of various parameters to be examined (e.g., matrix permeability, porosity, solid dielectric constant). The sensitivity coefficient $J_{i j}$, given by

$$
J_{i j}=\frac{\partial z_{i}}{\partial a_{j}},
$$


is a measure of the sensitivity of measurement $z_{i}$ to changes in parameter $a_{j}$. Examining $J_{i j}$ provides a way to understand relative parameter sensitivity before performing inversions.

Using the perturbation method, we calculated the sensitivity coefficient for the data sets described above and for a selection of the parameters potentially most important for characterization: the matrix permeability $\left(k_{m}\right)$; fracture permeability $\left(k_{f}\right)$; matrix porosity $(\phi)$; the active fracture parameter $(\gamma)$; the matrix and fracture parameters $\alpha_{m}$ and $\alpha_{f}$ of the van Genuchten function, which serve as scaling factors in the respective capillary pressure-water saturation relationships; ${ }^{\text {xxv }}$ and the dielectric constant $\kappa_{s}$ of the solid component of the rock.

The sensitivity coefficients (scaled by the expected standard deviation of the data and the parameters, $\sigma_{z}$ and $\sigma_{a}$, respectively) are depicted in Figs. 5 and 6. Fig. 5 shows for each parameter the sum over all survey times of the sensitivity of each data set separately (GPR, water content, and temperature) and of data sets combined. Note that the overall contribution from the GPR data sets is larger than for the water content and temperature data because of the larger number of GPR data available for the considered survey times. Of the hydrological parameters, the data are in general most sensitive to the $k_{m}, k_{f}$, and $\phi$. It is interesting to note that the temperature data have higher sensitivity to $\alpha_{\mathrm{f}}$ than to $\alpha_{\mathrm{m}}$, as opposed to the water content data that have lower sensitivity to $\alpha_{f}$ than to $\alpha_{m}$. The increased sensitivity of the temperature data to $\alpha_{f}$ can be explained by the fact that this parameter determines how much water and gas, and thus heat, is transported through fractures. The fact that $\alpha_{m}$ largely controls the amount of water present in the rock matrix explains the increased sensitivity of the water content data to this parameter. The parameter to which the data sets are consistently least sensitive is $\gamma$, indicating that its estimation through inversion may be most difficult. This is consistent with a previous investigation in which the parameter $\gamma$ was also found to be insensitive to data collected at Yucca 
Mountain. ${ }^{\text {xxxix }}$ As expected, the GPR data are sensitive to the petrophysical parameter $\kappa_{s}$, while the temperature and water content data are not.

The sensitivity of the available data to the parameters of interest is also seen to be a function of time. For example, the scaled sensitivity coefficient for GPR data for each parameter is shown as a function of survey time in Fig. 6. Note that as opposed to the logarithmic scale for the y-axis in Fig. 5, the scale for the y-axis is linear in Fig. 6, resulting in better visualization of the sensitivity with time, but also in less emphasis on the parameters with lower total sensitivity. For the pre-heater survey test (P0 at 0 days), the GPR data are only sensitive to $\kappa_{s}$ and the porosity and $\phi$, whereas for later times, especially beyond P2 at 426 days, the GPR data become very sensitive to $k_{m}$, and moderately sensitive to other hydrological parameters. Sensitivity to $\phi$ decreases slightly with time, and sensitivity to $\kappa_{s}$ remains relatively constant. Three distinct phases can be identified: the initial phase in which the initial conditions affect parameters such as $\phi$ and $\kappa_{s}$; the early heating phase in which the heating-induced perturbation causes dynamic flow phenomena (e.g., moisture redistribution), to which hydraulic parameters such as $k_{m}$ and $k_{f}$ are sensitive; and the late-heating phase in which the sensitivity of the hydraulic parameters begins to decrease as the dry-out zone covers an increasingly larger portion of the sampled region.

As a first step toward a full inversion of the heater test data, we estimated through inversion one unknown parameter $\left(k_{m}\right)$ while fixing the remaining parameters with values similar to those used in a previous modeling study for the site. ${ }^{\mathrm{xvi}}$ We use a simplified version of the approach developed by Kowalsky et al. ${ }^{\text {xiv }}$ for joint inversion of multiple data types in which only one parameter is estimated by minimizing the objective function, which consisted of the difference between the measured and simulated data (temperature, water content, and GPR travel times). The Levenberg-Marquardt algorithm was used to minimize the objective function. ${ }^{\mathrm{x}-\mathrm{xli}}$ 
In Figs. 7-9 a comparison is given of the measured data and the data simulated using the parameter obtained by inversion and the remaining parameters equaling their initial values. Note that the GPR travel times match best for the pre-heater test data set (data points labeled P0 in Fig. 7), but there are significant deviations for the remaining survey times (P1-P4), implying that additional parameters must be estimated to improve the match. The water content is slightly under-predicted in regions where the drying front has yet to reach the boreholes (Fig. 8). However, once the drying front reaches the middle of Borehole 4, the predicted water content is somewhat higher than the measured values. The temperature data show a good match overall (Fig. 9), but the temperatures are slightly under-predicted in some regions during heating, such as in the vertical borehole directly above the heated drift (Borehole 137).

Estimation of additional parameters is expected to improve the match between the simulated and measured data.

\section{CONCLUSION}

We have developed an approach for combining geophysical and hydrological measurements in a framework that provides quantitative estimates of parameters needed to model complex phenomena occurring in heated, fractured porous media. The large-scale heater test performed at Yucca Mountain, Nevada, provides a unique data set to which our approach can be applied and tested. Preliminary results indicate that estimation of thermal-hydrological and petrophysical parameters is possible through the combination of geophysical, hydrological and thermal measurements. Ongoing efforts include: (1) comprehensive inversions to estimate the most relevant thermal-hydrological parameters for the DST; (2) examining the possibility and importance of accounting for spatial heterogeneity in the material properties at the site (recently 
shown to be significant by Birkholzer ${ }^{\text {xlii }}$ ) during inversion; and, (3) further investigations of the petrophysical models of the dielectric constant and its temperature dependence.

\section{ACKNOWLEDGMENT}

The authors would like to thank Michael Commer for his careful review of this manuscript. This work was supported by Laboratory Directed Research and Development (LDRD) funding from Berkeley Lab, provided by the Director, Office of Science, of the U.S. Department of Energy under Contract No. DE-AC02-05CH11231.

\section{REFERENCES}

i J. E. PETERSON, B. N. P. PAULSSON, and T. V. MCEVILLY, "Applications of algebraic reconstruction techniques to crosshole seismic data," Geophysics, 50, 1566-1580 (1985).

ii S. S. HUBBARD, Y. RUBIN, and E. MAJER, "Ground-penetrating-radar assisted saturation and permeability estimation in bimodal systems," Water Resour. Res., 33, 971-990 (1997).

iii J. CHEN, S. HUBBARD, Y. RUBIN, C. MURRAY, E. RODEN, and E. MAJER, "Geochemical characterization using geophysical data and Markov Chain Monte Carlo methods: A case study at the South Oyster bacterial transport site in Virginia," Water Resour. Res., 40, W12412, doi:10.1029/2003WR002883 (2004).

iv J. E. PETERSON, "Pre-inversion Corrections and Analysis of Radar Tomographic Data," J. of Env. and Engin. Geophysics, 6(1), 1-18 (2001).

v F. D. DAY-LEWIS and J. W. LANE, JR., "Assessing the resolution-dependent utility of tomograms for geostatistics," Geophys. Res. Lett., 31(7), L07503. 10.1029/2004GL019617, (2004). 
vi S. MOYSEY and R. KNIGHT, "Modeling the field-scale relationship between dielectric constant and water content in heterogeneous system," Water Resour. Res., 40, W03510, doi:10.1029/2003WR002589 (2004).

vii N. LINDE, S. FINSTERLE, and S. HUBBARD, "Inversion of tracer test data using tomographic constraints," Water Resour. Res., 42, W04410, doi:10.1029/ 2004WR003806 (2006).

viii M. B. KOWALSKY, P. DIETRICH, G. TEUTSCH and Y. RUBIN, "Forward modeling of ground-penetrating radar data using digitized outcrop images and multiple scenarios of water saturation," Water Resour. Res., 37(6), 1615-1625 (2001).

ix M. B. KOWALSKY, Y. RUBIN and P. DIETRICH, "The use of ground-penetrating radar for characterizing sediments under transient flow conditions," in Aquifer Characterization, SEPM Special Pub. 80, Eds., J. S. Bridge and D. W. Hyndman, 107-127 (2004).

x J. A. HUISMAN, S. S. HUBBARD, J. D. REDMAN and A. P. ANNAN, "Measuring soil water content with ground penetrating radar: a review," Vadose Zone J., 2, 476-91 (2003).

xi A. BINLEY, G. CASSIANI, R. MIDDLETON, and P. WINSHIP (2002), "Vadose zone flow model parameterization using cross-borehole radar and resistivity imaging," J. of Hydrol., 267, 147-159.

xii S. LAMBOT, M. ANTOINE, I. VAN DEN BOSCH, E. C. SLOB, and M. VANCLOOSTER, "Electromagnetic Inversion of GPR Signals and Subsequent Hydrodynamic Inversion to Estimate Effective Vadose Zone Hydraulic Properties," Vadose Zone J., 3, 10721081 (2004).

xiii M. B. KOWALSKY, S. FINSTERLE, and Y. RUBIN, "Estimating flow parameter distributions using ground-penetrating radar and hydrological measurements during transient flow in the vadose zone," Adv. in Water Res., 27(6), 583-599 (2004).

xiv M. B. KOWALSKY, S. FINSTERLE, J. PETERSON, S. HUBBARD, Y. RUBIN, E. MAJER, A. WARD, and G. GEE, "Estimation of field-scale soil hydraulic and dielectric 
parameters through joint inversion of GPR and hydrological data," Water Resour. Res., 41, W11425, doi:10.1029/2005WR004237 (2005).

xv S. FINSTERLE and M. B. KOWALSKY, "Joint hydrological-geophysical inversion for soil structure identification," Vadose Zone J. (accepted).

xvi J. BIRKHOLZER and Y. W. TSANG, "Modeling the Thermal-hydrologic Processes in a Large-scale Underground Heater Test in Partially Saturated Fractured Tuff," Water Resour. Res., 36(6), 1431-1447 (2000).

${ }^{\text {xvii }}$ G. S. BODVARSSON, W. BOYLE, R. PATTERSON, and D. WILLIAMS, "Overview of scientific investigations at Yucca Mountain, Nevada, the potential repository for high-level nuclear waste," J. Contam. Hydrol., 38(1-3), 3-24 (1999).

${ }^{\text {xviii }}$ P. MONTAZER and W. E. WILSON, "Conceptual Hydrologic Model of Flow in the Unsaturated Zone, Yucca Mountain, Nevada," U.S. Geol. Surv. Water Resour. Invest. Rep., 844355 (1984).

xix Y. W. TSANG and J. BIRKHOLZER, "Predictions and Observations of the Thermalhydrologic Conditions in the Single Heater Test," J. of Contaminant Hydrology, 38(1-3), 385426 (1999).

xx K. PRUESS, C. OLDENBURG and G. MORIDIS, “TOUGH2 User's Guide, Version 2.0,” Rep. LBNL-43134, Lawrence Berkeley National Laboratory, Berkeley, Calif. (1999).

xxi K. PRUESS, "TOUGH2-A general purpose simulator for multiphase fluid and heat flow," Rep. LBL-29400, Lawrence Berkeley National Laboratory, Berkeley, Calif. (1991).

${ }^{\text {xxii }}$ H. H. LIU, C. DOUGHTY and G. S. BODVARSSON, "An active fracture model for unsaturated flow and transport in fractured rocks," Water Resour. Res., 34(10), 2633-2646 (1998).

xxiii J. BIRKHOLZER and Y. W. TSANG, "Pretest analysis of the thermal-hydrological conditions of the ESF Drift Scale Test," Report LBNL-41044, Lawrence Berkeley National Laboratory, Berkeley, Calif. (1997). 
${ }^{\text {xxiv }}$ S. MUKHOPADHYAY, and Y. W. TSANG, "Uncertainties in Coupled ThermalHydrological Processes Associated with the Drift Scale Test at Yucca Mountain, Nevada," J. of Contaminant Hydrology, 62-63, 595-612 (2003).

${ }^{x x y}$ M. TH. VAN GENUCHTEN, "A Closed-Form Equation for Predicting the Hydraulic Conductivity of Unsaturated Soils," Soil Sci. Soc., 44, 892 (1980).

${ }^{x x v i}$ R. H. BROOKS and A. J. COREY, "Hydraulic properties of porous media," Hydrol. Paper 3, Colo. State Univ., Fort Collins, CO (1964).

xxvii S. FINSTERLE, “iTOUGH2 User's Guide,” Report LBNL-40040, Lawrence Berkeley National Laboratory, Berkeley, Calif (1999).

xxviii S. FINSTERLE, "Multiphase inverse modeling: review and iTOUGH2 applications," Vadose Zone J., 3, 747-762 (2004).

${ }^{\text {xxix }}$ T. BERGMANN, J.O.A. ROBERTSSON and K. HOLLIGER, "Finite-difference modeling of electromagnetic wave propagation in dispersive and attenuating media," Geophysics, 63(3), 856-867 (1998).

${ }^{\mathrm{xxx}}$ A. ALHARTI and J. LANGE, "Soil water saturation: Dielectric determination," Water Resour. Res., 23, 591-595 (1987).

${ }^{x \times x i}$ K. R. ROTH, R. SCHULIN, H. FLUHLER and W. ATTINGER, "Calibration of time domain reflectometry for water content measurement using a composite dielectric approach," Water Resour. Res., 26, 2267-2273 (1990).

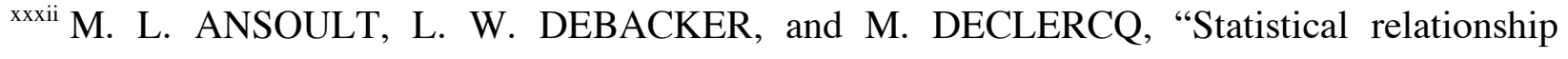
between apparent dielectric constant and water content in porous media," J. Soil Sci. Soc. Am., 49, 47- 50 (1984).

xxxiii J. R. BIRCHAK, L. G. GARDNER, J. W. HIPP, and J. M. VICTOR, "High dielectric constant microwave probes for sensing soil moisture," Proc. IEEE, 62(1), 93- 98 (1974). 
${ }^{\text {xxxiv }}$ C. Y. CHAN and R. J. KNIGHT, "Determining water content and saturation from dielectric measurements in layered materials," Water Resour. Res., 35(1), 85- 94 (1999).

${ }^{x x x v}$ R. C. WEAST, "CRC Handbook of Chemistry and Physics," 67th ed., CRC Press, Boca Raton, Fla. (1986).

xxxvi J. M. WRAITH and D. OR, "Temperature effects on soil bulk dielectric permittivity measured by time domain reflectometry: Experimental evidence and hypothesis development," Water Resour. Res., 35(2), 361-370 (1999).

xxxvii J. J. ROBERTS and W. LIN, "X-Ray Radiography of Fracture Flow and Matrix Imbibition in Topopah Spring Tuff Under a Thermal Gradient," International Journal of Rock Mechanics and Mining Sciences, 34, (3/4), 482 (1997).

xxxviii D. MCLAUGHLIN and L. R. TOWNLEY, "A reassessment of the groundwater inverse problem," Water Resour. Res., 32(5), 1131-61 (1996).

xxxix Y. S. WU, G. LU, K. ZHANG, H. LIU, T. XU, and E. SONNENTHAL, "UZ flow models and submodels," Report MDL-NBS-HS-000006 REV 02, Bechtel SAIC Company, Las Vegas, NV (2004).

xl K. LEVENBERG, "A method for the solution of certain problems in least squares," $Q$. Appl. Math., 2, 164-168 (1944).

xli D. MARQUARDT, "An algorithm for least squares estimation of nonlinear parameters," SIAM J. Appl. Math., 11, 431- 441 (1963).

xlii J. BIRKHOLZER, "Estimating Liquid Fluxes in Thermally Perturbed Fractured Rocks Using Measured Temperature Profiles,” J. of Hydrology, 327, 496-515 (2006). 


\section{LIST OF FIGURES}

Figure 1. Three-dimensional perspective of the DST. The wing heaters are shown in red, while the boreholes in which the GPR, water content, and temperature data were collected are shown in blue, orange, and yellow, respectively. The length of the heated drift is 50 meters, its diameter is 5 meters, and the distance between the heated drift and the observation drift is approximately 30 meters.

Figure 2. Thermal-hydrological (TH) model domain and measurement locations: (a) numerical grid for TH model, ${ }^{\mathrm{xvi}}$ (b) locations of water content (neutron-probe derived) and temperature measurements (indicated by blue- and red-shaded grid blocks, respectively); and (c) antenna locations for ground-penetrating radar data used for inversion (green lines connect transmitting and receiving antenna positions).

Figure 3. Time-lapse ground-penetrating radar data: $(\mathrm{a}-\mathrm{c})$ all GPR travel times between positions in Boreholes 3 and 4; (d-f) subsets of data used for inversion. Note that: (a) and (d) correspond to data collected before the onset of heating (P0); (b) and (e) correspond to data collected 36 months after the onset of heating (P3); (c) and (f) correspond to data collected 58 months after the onset of heating (P5). Additional data sets (P1 and P3) are considered in this study but not shown in this figure.

Figure 4. Water content distributions in Boreholes 3-5 derived from neutron-probe (NP) data. The data collected at all times during the heating phase of the test are shown in the left column, with color representing water content. Data collected at the 5 survey times (P0-P4) used for inversion in this study are shown in the right column.

Figure 5. Scaled sensitivity coefficient for data (z), as indicated in the legend, for each parameter (a), as indicated by the x-axis. Note that there is zero sensitivity for temperature and water content data to $\kappa_{\mathrm{s} \text {. }}$

Figure 6. Scaled sensitivity coefficient for GPR data (z) and each parameter (a), as indicated in the legend, as a function of survey time.

Figure 7. Measured and simulated temperatures in Boreholes 137-144 for 5 survey times (P0P4). Multiple data points collected in the space of an individual grid block in the thermalhydrological model were averaged for comparison with the simulated values. 
Figure 8. Comparison of measured (dots) and simulated GPR travel times (circles) collected between Boreholes 3 and 4 for 5 survey times (P0-P4).

Figure 9. Measured (symbols) and simulated (lines) water content values in Boreholes 3-5 for 5 survey times (P0-P4). Multiple data points collected in the space of an individual grid block in the thermal-hydrological model were averaged for comparison with the simulated values. 


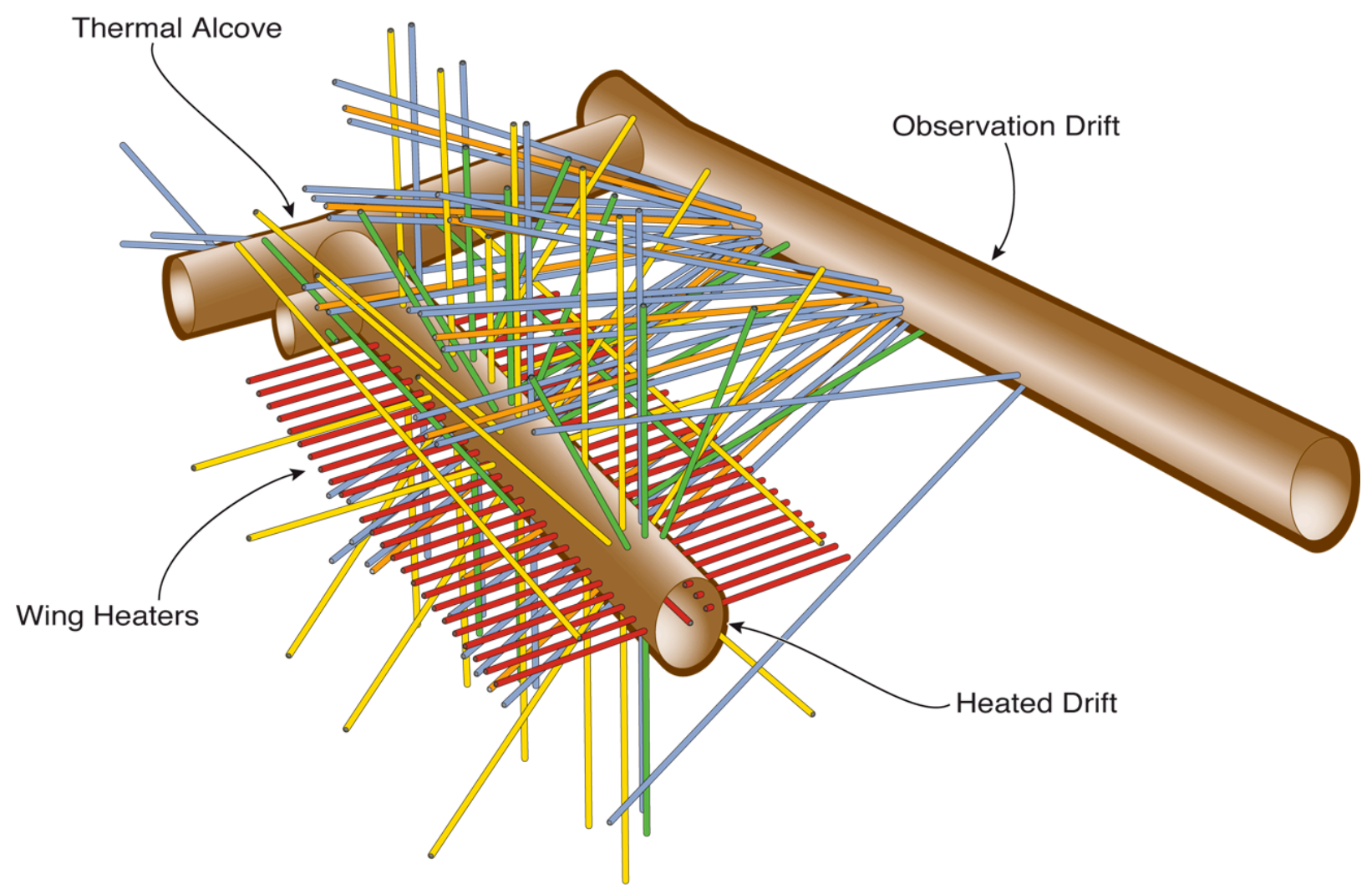

Figure 1. Three-dimensional perspective of the DST. The wing heaters are shown in red, while the boreholes in which the GPR, water content, and temperature data were collected are shown in blue, orange, and yellow, respectively. The length of the heated drift is 50 meters, its diameter is 5 meters, and the distance between the heated drift and the observation drift is approximately 30 meters. 

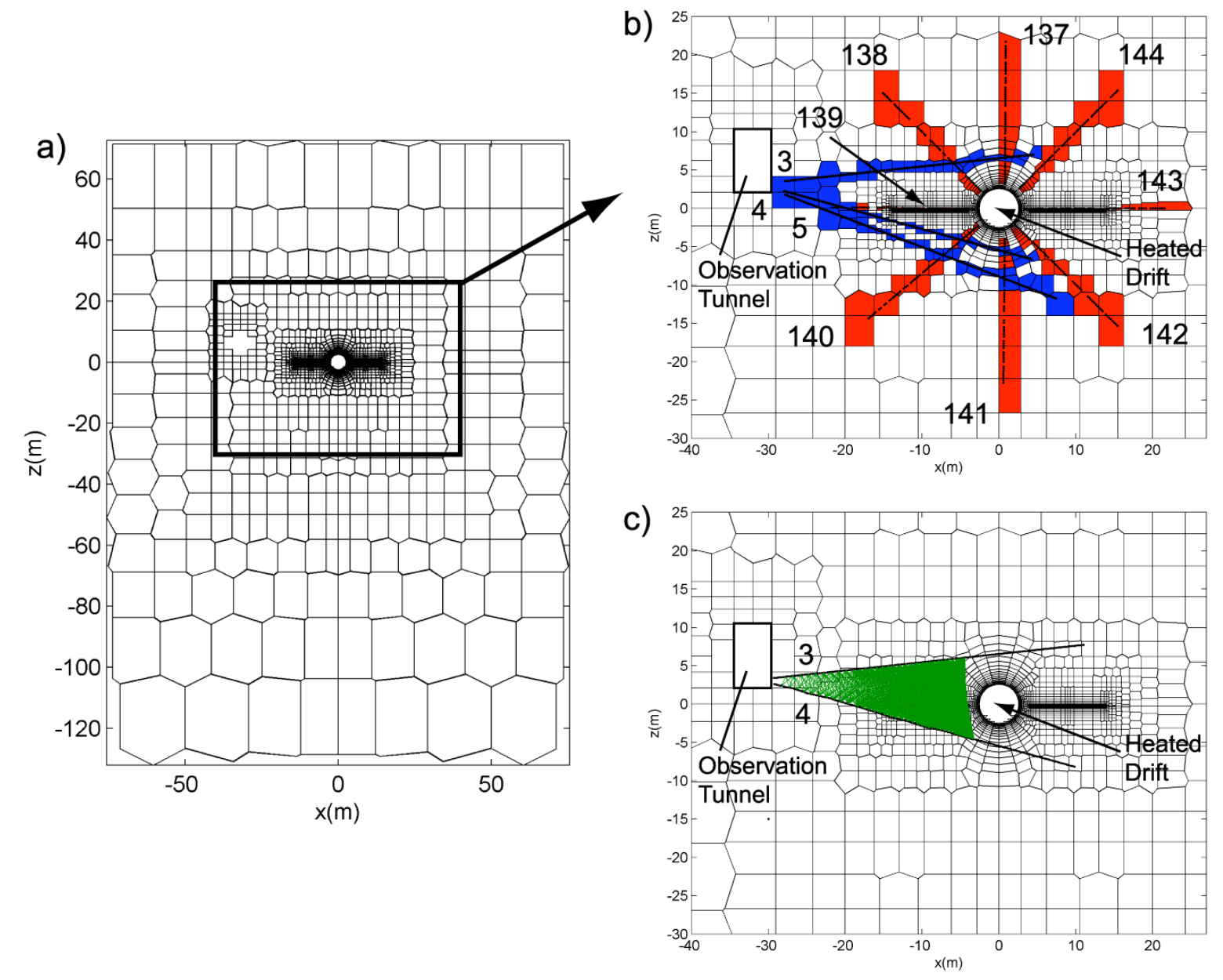

Figure 2. Thermal-hydrological (TH) model domain and measurement locations: (a) numerical grid for TH model; ${ }^{\mathrm{xvi}}$ (b) locations of water content (neutron-probe derived) and temperature measurements (indicated by blue- and red-shaded grid blocks, respectively); and (c) antenna locations for ground-penetrating radar data used for inversion (green lines connect transmitting and receiving antenna positions). 

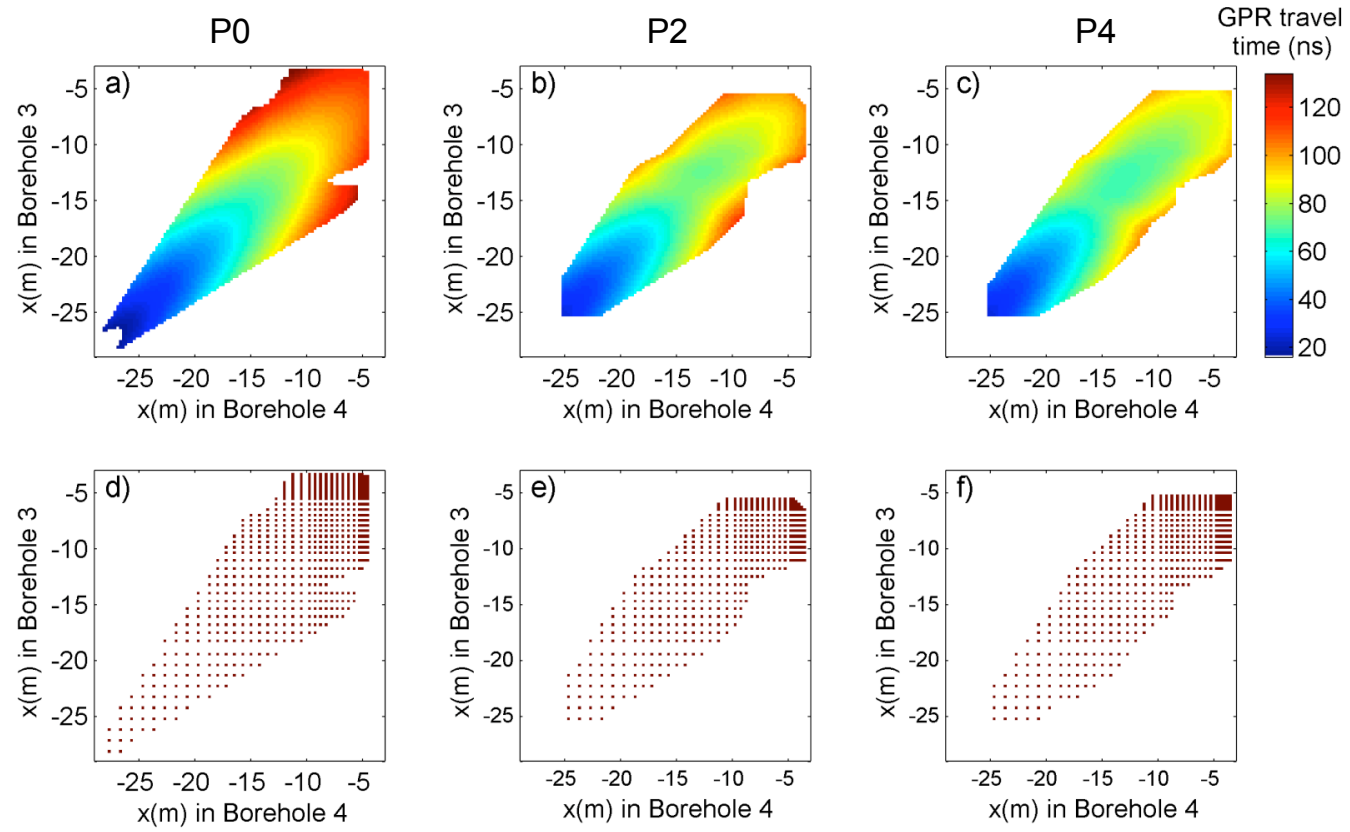

Figure 3. Time-lapse ground-penetrating radar data: $(\mathrm{a}-\mathrm{c})$ all GPR travel times between positions in Boreholes 3 and 4; (d-f) subsets of data used for inversion. Note that: (a) and (d) correspond to data collected before the onset of heating (P0); (b) and (e) correspond to data collected 36 months after the onset of heating (P3); (c) and (f) correspond to data collected 58 months after the onset of heating (P5). Additional data sets (P1 and P3) are considered in this study but not shown in this figure. 

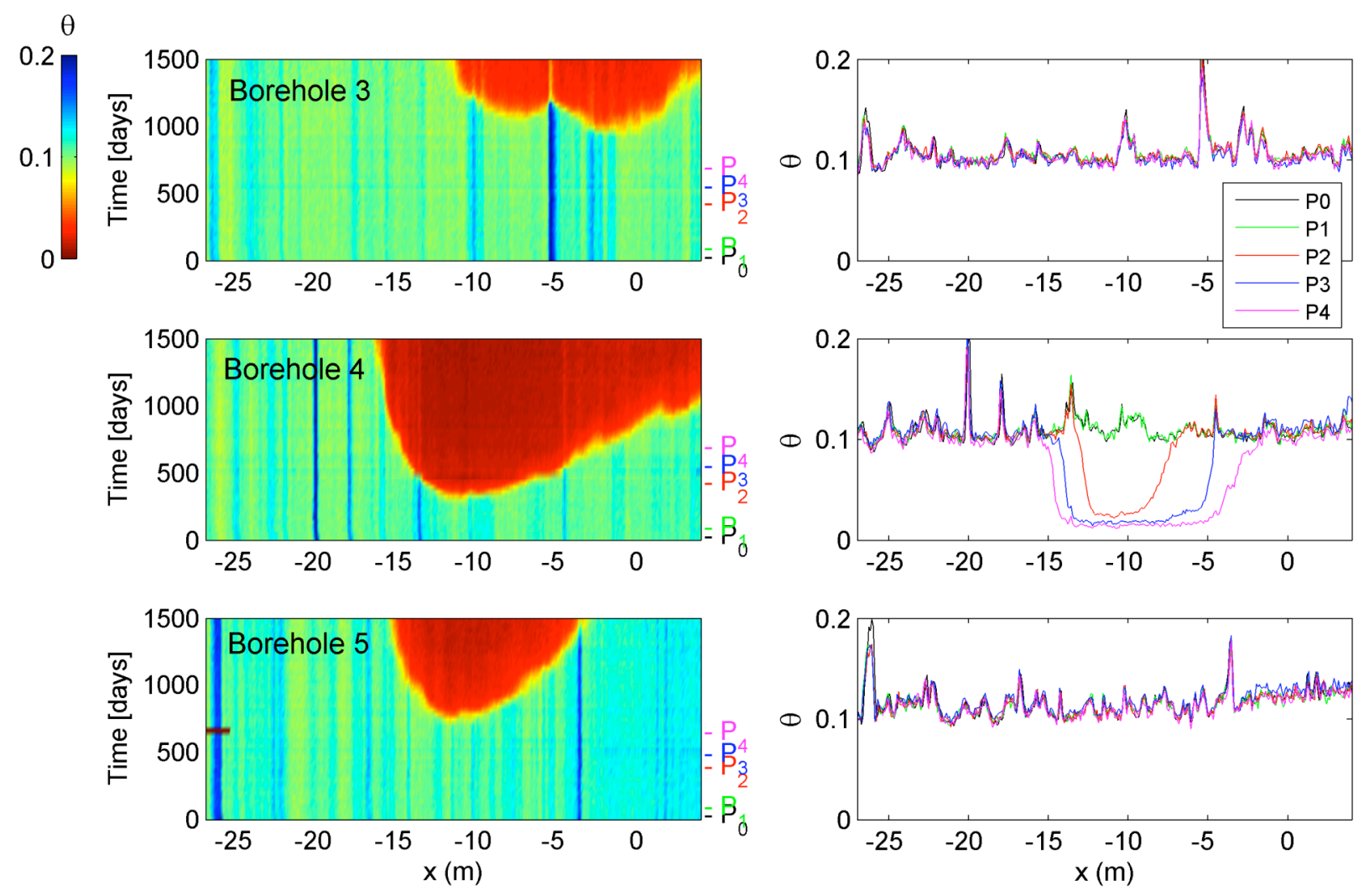

Figure 4. Water content distributions in Boreholes 3-5 derived from neutron-probe (NP) data. The data collected at all times during the heating phase of the test are shown in the left column, with color representing water content. Data collected at the 5 survey times (P0-P4) used for inversion in this study are shown in the right column. 


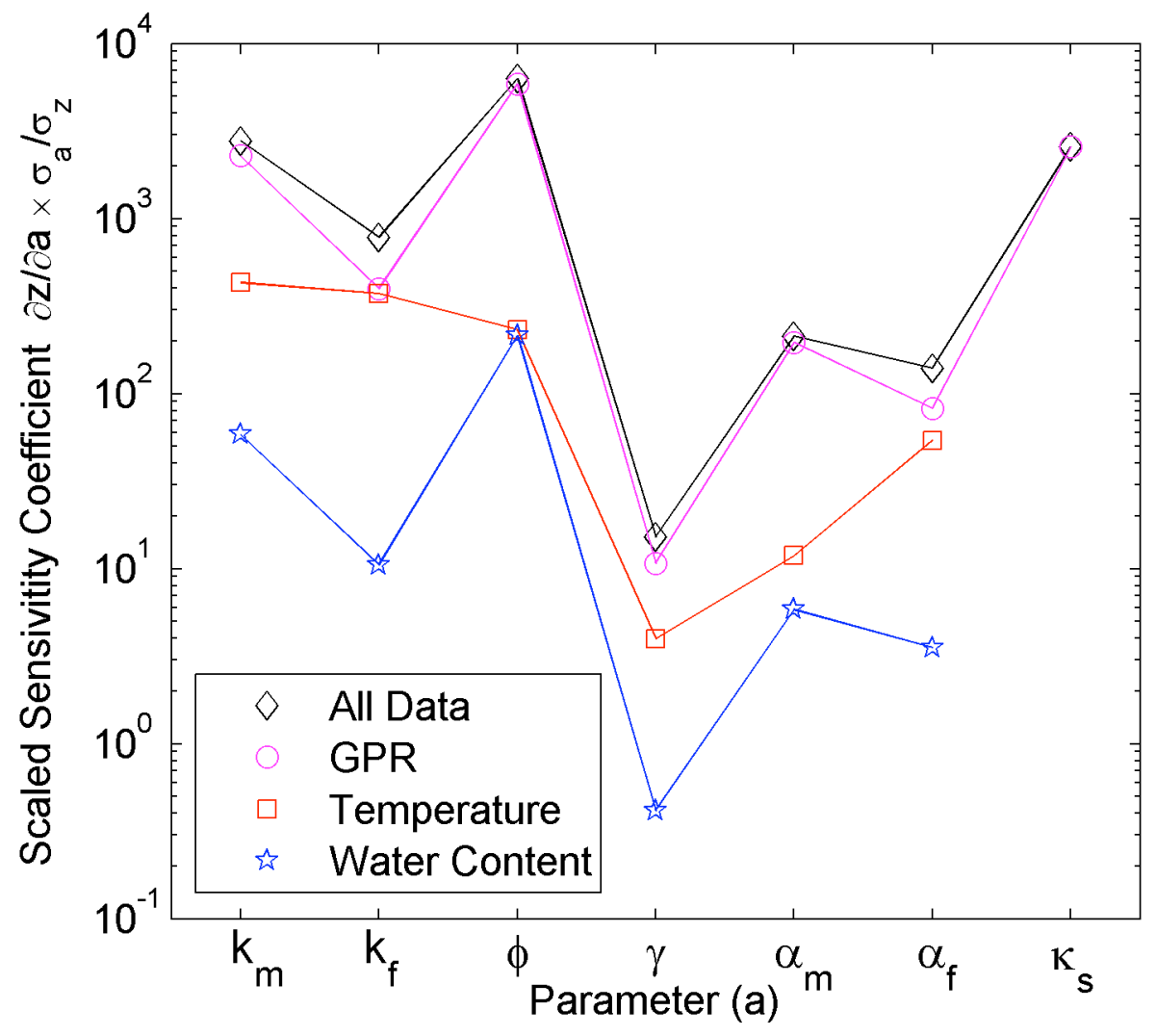

Figure 5. Scaled sensitivity coefficient for data (z), as indicated in the legend, for each parameter (a), as indicated by the x-axis. Note that there is zero sensitivity for temperature and water content data to $\kappa_{\mathrm{s} .}$ 


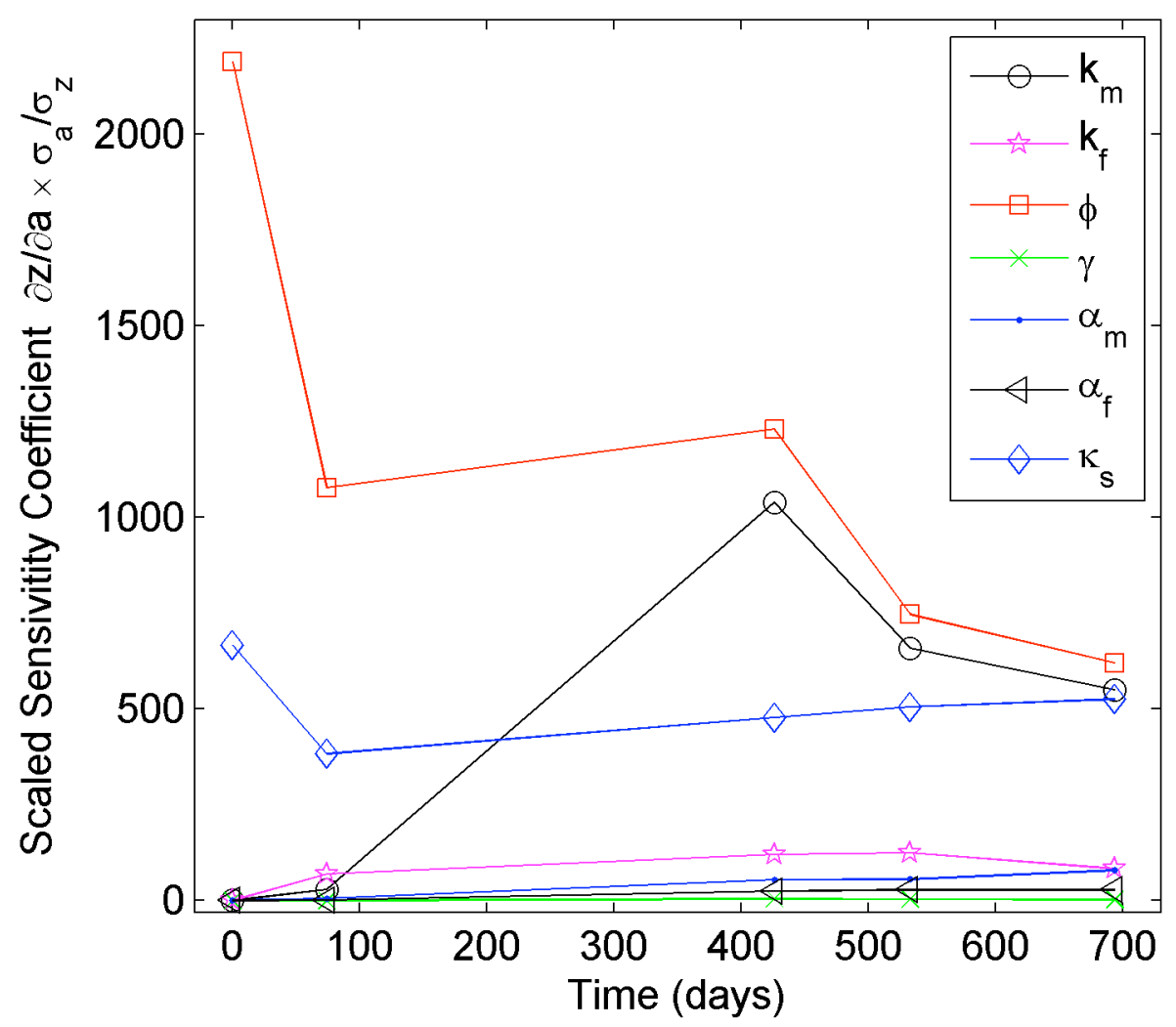

Figure 6. Scaled sensitivity coefficient for GPR data (z) and each parameter (a), as indicated in the legend, as a function of survey time. 


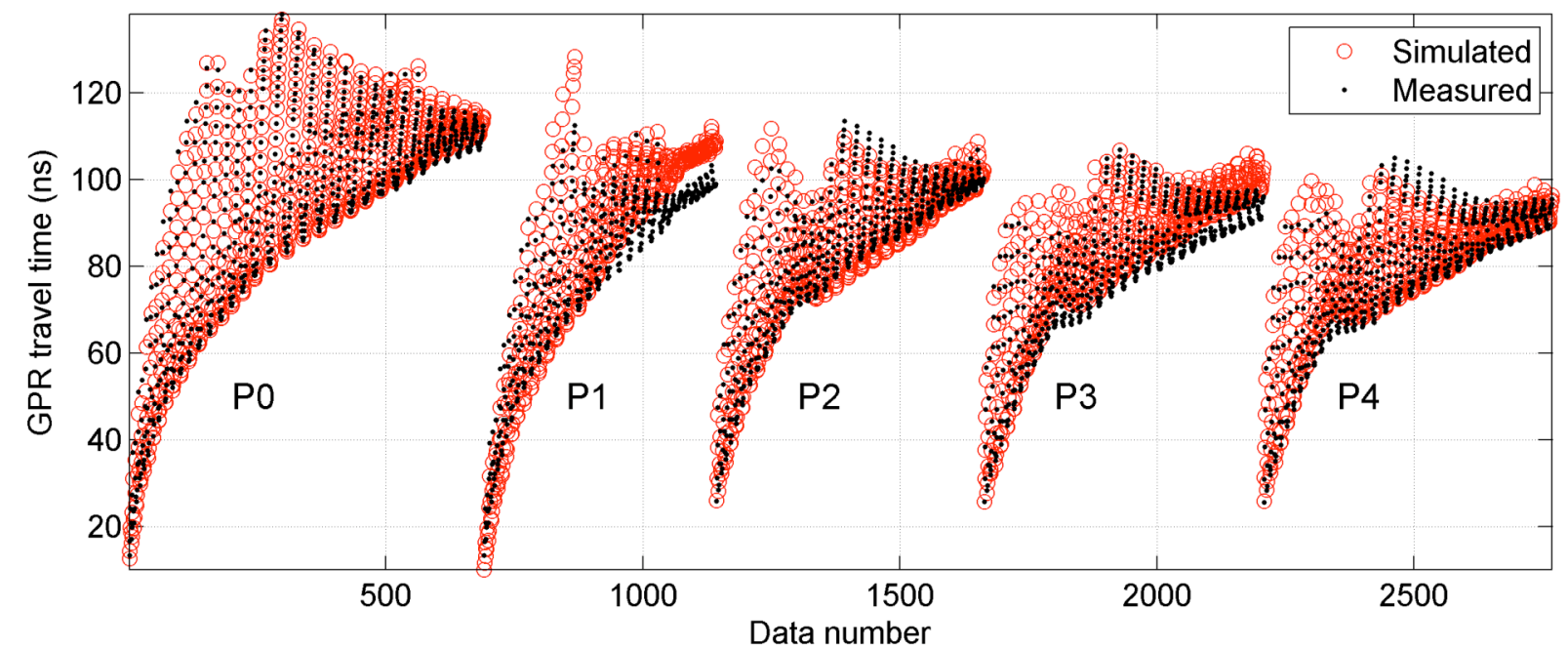

Figure 7. Comparison of measured (dots) and simulated GPR travel times (circles) collected between Boreholes 3 and 4 for 5 survey times (P0-P4). 

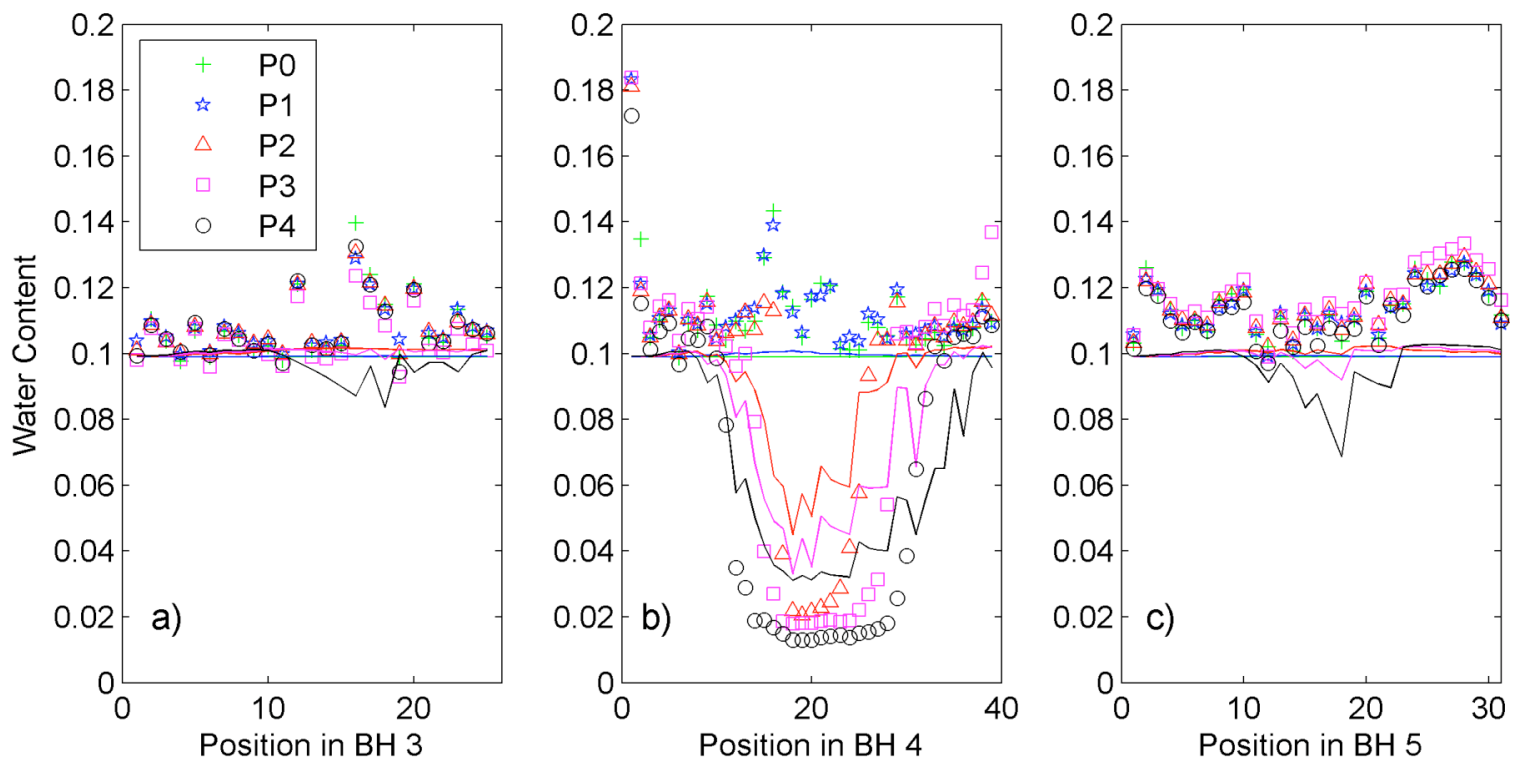

Figure 8. Measured (symbols) and simulated (lines) water content values in Boreholes 3-5 for 5 survey times (P0-P4). Multiple data points collected in the space of an individual grid block in the thermal-hydrological model were averaged for comparison with the simulated values. 


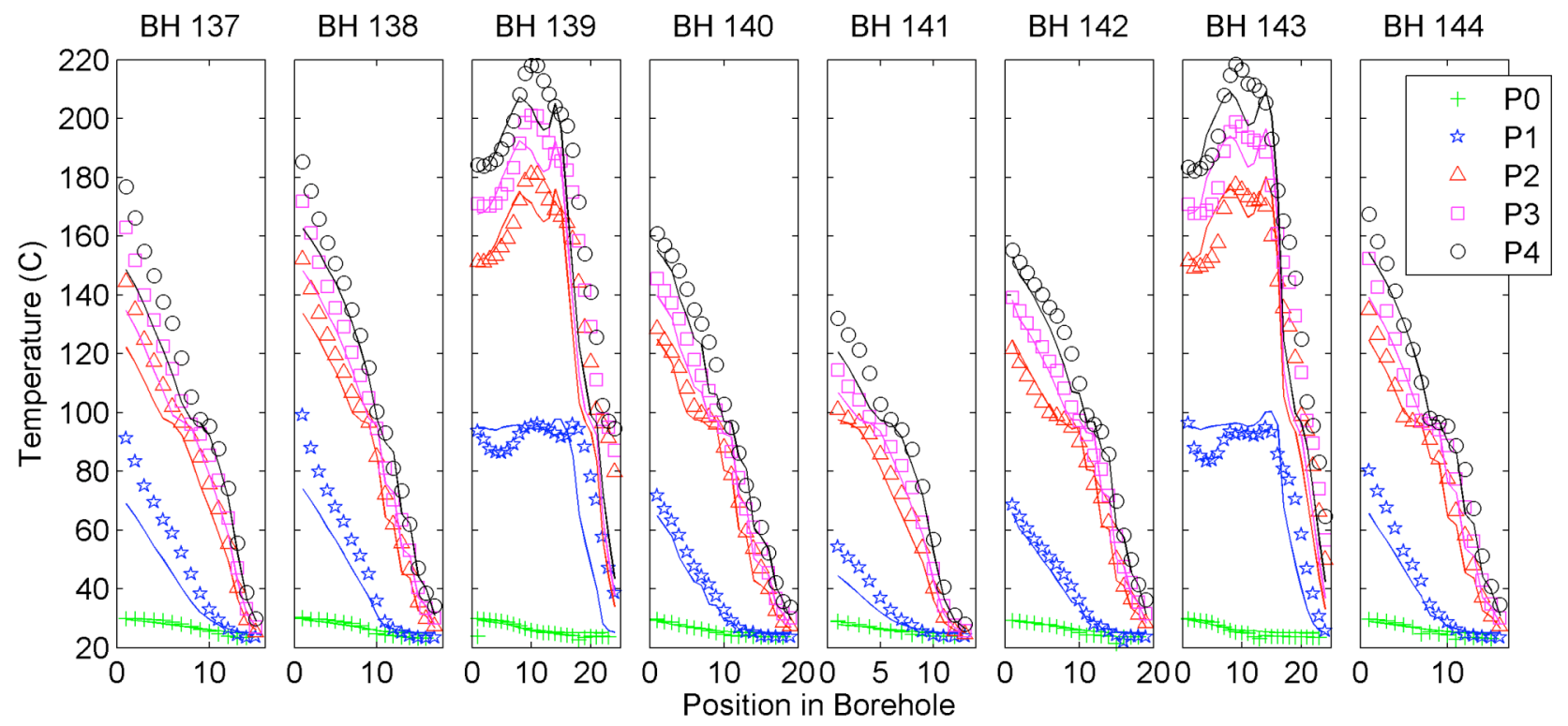

Figure 9. Measured and simulated temperatures in Boreholes 137-144 for 5 survey times (P0P4). Multiple data points collected in the space of an individual grid block in the thermalhydrological model were averaged for comparison with the simulated values. 